\title{
Sistemas certificáveis de gestão ambiental e da qualidade: práticas para integração em empresas do setor moveleiro
}

\author{
Paulo Fernando Fuzer Grael ${ }^{\mathrm{a}, *}$, Otávio José de Oliveira ${ }^{\mathrm{b}}$ \\ a,*paulograel@conectcor.com.br, UNESP, Brasil \\ botavio@feb.unesp.br, UNESP, Brasil
}

\begin{abstract}
Resumo
0 principal objetivo deste artigo é propor, a partir do referencial teórico e de um estudo de caso em uma empresa moveleira, práticas para integração de sistemas certificáveis de gestão ambiental e da qualidade. A coleta de dados do estudo de caso se deu por meio de entrevistas semiestruturadas com o responsável direto pelos dois sistemas e com alguns colaboradoreschave do nível operacional, além de análise documental e de visitas in loco. Ao final deste artigo, são propostas práticas para integração desses sistemas, relacionadas aos seguintes elementos: alta administração; apoio administrativo, financeiro e pessoal; serviço de consultoria; coordenação do programa de integração; interface entre os sistemas; capacitação técnico-gerencial; sistema de liderança, prospecção, avaliação e desenvolvimento de fornecedores; sistema de informação; indicadores; comunicação com o cliente, e integração contínua.
\end{abstract}

Palavras-chave

Integração de sistemas de gestão. Sistemas certificáveis. Gestão da qualidade. Gestão ambiental.

\section{Introdução}

Diante das profundas mudanças na conjuntura econômica, as empresas vêm sendo pressionadas a alterar seus sistemas internos de gestão e, consequentemente, seus processos de produção no sentido de reduzir custos e adequar seus produtos às condições e necessidades do mercado.

É neste cenário que os sistemas de gestão da qualidade e gestão ambiental têm sido cada vez mais objeto da atenção dos gestores, que os têm adotado como forma de gerar vantagem em relação à concorrência.

Os sistemas de gestão da qualidade (SGQ), a partir da identificação das reais necessidades dos clientes, proporcionam contínua melhoria e racionalização de projetos, processos e produtos/serviços. Os sistemas de gestão ambiental (SGA), por sua vez, possibilitam a realização de processos sustentáveis e a redução dos custos de produção a partir da melhor utilização dos recursos naturais e da aplicação dos conceitos de produção mais limpa.

A perspectiva destes resultados torna-se ainda mais importante ao se considerar o setor moveleiro, objeto de estudo deste trabalho, em virtude de sua relevância econômica e de suas características peculiares, como a intensa degradação do meio ambiente e os altos índices de desperdício em suas atividades de produção.

0 problema, no entanto, é conseguir a efetiva integração destes sistemas. Em geral, eles são implantados em momentos distintos, por empresas de consultorias diferentes, e trabalham em paralelo e sem integração, reduzindo, dessa forma, suas potencialidades e os resultados que deles poderiam advir.

Portanto, a questão que norteou o desenvolvimento desta pesquisa foi: de que forma é possível integrar sistemas certificáveis de gestão ambiental e da qualidade em empresas do setor moveleiro de maneira a gerar efetivo diferencial competitivo?

Em função do exposto, o principal objetivo deste artigo é propor, a partir do referencial teórico e de um estudo de caso em uma empresa moveleira, práticas para integração de sistemas certificáveis de gestão ambiental e da qualidade.

Para garantir seu foco, procurou-se delimitar o escopo da pesquisa em relação aos seguintes elementos: objeto de estudo (sistemas certificáveis de gestão ambiental e da qualidade) e segmento de atuação das empresas (setor moveleiro). 
A integração de sistemas de gestão ambiental e da qualidade não é um tema novo no cenário científico. Contudo, a proposição de práticas customizadas para aplicação direta em empresas do setor moveleiro confere um considerável grau de originalidade à pesquisa e possibilita o vislumbramento de promissoras contribuições para o desenvolvimento setorial e para o incremento dos estudos acadêmicos aplicados relacionados ao tema.

Para embasar a realização do trabalho, tendo-se a questão de pesquisa posta e o objetivo pretendido, é apresentada uma revisão teórica sintetizada acerca de normalização e certificação de sistemas, gestão da qualidade com base na norma 1S0 9001, gestão ambiental com base na norma ISO 14001 e integração de sistemas de gestão normalizados da qualidade e meio ambiente.

\section{Método de pesquisa}

Neste trabalho, realizou-se uma pesquisa qualitativa com base no método de estudo de caso. Para justificar a escolha destes instrumentos metodológicos, seguem algumas definições e um breve esclarecimento de sua relação com este trabalho.

A pesquisa qualitativa se preocupa fundamentalmente com a compreensão e a interpretação do fenômeno, tendo como principal objetivo compreender, explorar e especificá-lo sob a perspectiva da influência de crenças, percepções, sentimentos e valores nos dados coletados (SANTOS; ROSSI; JARDILINO, 2000). Esta definição se aplica ao contexto deste trabalho tendo-se em vista seu caráter exploratório e interpretativo.

0 estudo de caso tem característica holística, pois tenta entender e explicar o que acontece e por que acontece, considerando-se o seu todo. Assim, torna-se importante compreender e identificar os fatores contextuais que cercam a unidade de análise. Estudos de caso podem ser descritivos, exploratórios ou explicativos, isto é, podem gerar teoria ou contribuir para sua modificação (GRÜNBAUM, 2007). Neste artigo, pretende-se contribuir com a construção da teoria a partir da sugestão de práticas para integração de sistemas de gestão ambiental e da qualidade.

$\mathrm{Na}$ metodologia de estudo de caso, o objeto de estudo está sempre relacionado com pessoas, mais especificamente com a interpretação da percepção dos atores sociais de um determinado fenômeno ou os significados que estes atribuem a ele (GRÜNBAUM, 2007).

Yin (2003) salienta que é necessário considerar os seguintes princípios fundamentais para o trabalho de coleta de dados em estudos de caso: a) utilização de duas ou mais fontes de dados que convirjam em relação ao mesmo conjunto de fatos ou descobertas; b) utilização de banco de dados para os casos, isto é, uma reunião formal de evidências, e c) encadeamento de evidências, ou seja, ligações explícitas entre as questões feitas, os dados coletados e as conclusões a que se chegaram. Durante a realização dos trabalhos desta pesquisa, procurou-se observar estas recomendações.

As fontes de coleta de dados e as evidências utilizadas nesta pesquisa foram: entrevistas semiestruturadas, análise de documentos e visitas in loco. Foram realizadas entrevistas com o coordenador dos sistemas de gestão ambiental e da qualidade da empresa e com alguns colaboradores diretamente responsáveis por processos-chave em relação a estes sistemas. Os pesquisadores tiveram total acesso ao chão-de-fábrica e à documentação relativa aos dois sistemas.

A principal função do estudo de caso neste trabalho foi exploratória, de forma a familiarizar os pesquisadores com o universo e as questões estudadas, além de apoiar a revisão teórica. As práticas sugeridas foram elaboradas com base na revisão da literatura e corroboradas pelas informações obtidas no estudo de caso. A Figura 1 apresenta os macroestágios de desenvolvimento metodológico desta pesquisa.
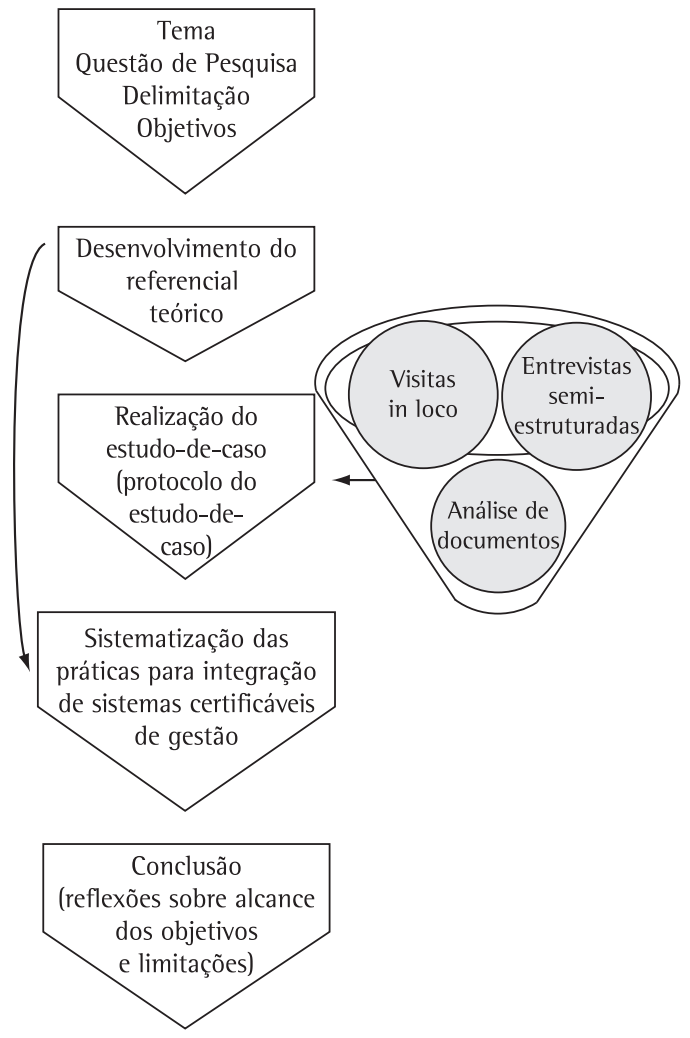

Figura 1. Macroestágios de desenvolvimento metodológico da pesquisa. 


\section{Normalização e certificação de sistemas}

Segundo Oliveira e Melhado (2004), a normalização é a atividade que estabelece, em relação a problemas existentes ou potenciais, prescrições destinadas à utilização comum e repetitiva, com vistas à obtenção do grau ótimo em um dado contexto.

A normalização é um excelente argumento para vendas ao mercado internacional e também um importante instrumento para regular a importação de produtos que não estejam em conformidade com as normas do país comprador.

Segundo Franceschini, Galetto e Cecconi (2006), no final dos anos 70, vários países estavam criando um padrão de normalização interno básico para aplicação em setores específicos que necessitavam de alguns requisitos mínimos para garantir a qualidade de seus produtos. A International Organization for Standardization interessou-se pela regulamentação destas atividades em diferentes setores industriais e formulou a primeira série de normas ISO 9000, em 1987.

Segundo Sun (2000), um sistema de gestão é uma ferramenta que influencia de maneira sistemática, integrada e consistente as perspectivas que envolvem todos e tudo em uma organização, oferecendo um genérico conceito para melhoria das performances.
Um sistema de gestão é a interação de partes, recursos, atividades e processos com determinado objetivo comum. Diferentemente, o processo é a transformação de entradas, que, após processamento, são transformadas em saídas: produto, senviços, informação, etc. (CASTRO; OLIVEIRA, 2007).

A certificação de um sistema é o reconhecimento de que ele atende a uma norma de referência e é concedida por uma entidade certificadora credenciada. 0 credenciamento das entidades certificadoras está a cargo de um órgão fiscalizador, função exercida no Brasil pelo Instituto Nacional de Metrologia (INMETRO).

As normas 9001 (gestão da qualidade) e ISO 14001 (gestão ambiental) contemplam sistemas de controle de processos e envolvem a gestão de suprimentos, recursos humanos, informações, documentos, projeto, produção e distribuição de produtos e serviços, para atender as necessidades dos clientes e da empresa (MAGD; CURRY, 2003).

Essas normas possuem focos similares em relação à racionalização do processo produtivo e incentivam a utilização de várias ferramentas, métodos e práticas para melhoria contínua em comum, além de estarem baseadas no ciclo PDCA (Plan, Do, Check e Action) (CURKOVIC; SROFE; MELNYK, 2005).

0 Quadro 1 ilustra as principais fases do processo de implantação de um sistema de gestão certificável.

Quadro 1. Fases e atividades do processo de implantação de sistemas de gestão certificáveis.

\begin{tabular}{|c|c|c|}
\hline Fase & Envolvidos & Atividades \\
\hline Planejamento & Administração & $\begin{array}{l}\text { - comprometimento com a implantação do sistema } \\
\text { - seleção de modelo de conformidade (norma) } \\
\text { - composição de equipe de gerenciamento (comitê da qualidade e } \\
\text { ambiental) } \\
\text { - estabelecimento de cronograma geral } \\
\text { - avaliação de necessidades de treinamento em relação à norma } \\
\text { - seleção do órgão certificador }\end{array}$ \\
\hline $\begin{array}{l}\text { Análise de desvios e } \\
\text { ação corretiva }\end{array}$ & Comitê da qualidade & $\begin{array}{l}\text { - avaliação do sistema frente ao modelo de conformidade selecionado } \\
\text { (norma) } \\
\text { - instituição das mudanças necessárias (quebra de paradigmas iniciais) }\end{array}$ \\
\hline $\begin{array}{l}\text { Documentação e } \\
\text { registros }\end{array}$ & Comitê da Qualidade & $\begin{array}{l}\text { - estruturação de documentos e sistema de controle } \\
\text { - instituição de controle dos registros } \\
\text { - treinamento relativo a documentos e procedimentos criados }\end{array}$ \\
\hline Implantação & $\begin{array}{l}\text { Administração e } \\
\text { Comitê da qualidade }\end{array}$ & $\begin{array}{l}\text { - implementação e monitoramento dos sistemas de gestão } \\
\text { - manutenção dos sistemas de gestão implantados }\end{array}$ \\
\hline $\begin{array}{l}\text { Auditoria de pré- } \\
\text { qualificação }\end{array}$ & Auditor pré-qualificado & $\begin{array}{l}\text { - deve assegurar que todas as operações de documentação estejam de } \\
\text { acordo com o modelo de conformidade selecionado }\end{array}$ \\
\hline $\begin{array}{c}\text { Análise da } \\
\text { documentação }\end{array}$ & Certificador & $\begin{array}{l}\text { - análise prévia do documento geral (manual) e toda documentação } \\
\text { operacional e de apoio e processos }\end{array}$ \\
\hline $\begin{array}{l}\text { Auditoria de } \\
\text { certificação }\end{array}$ & Certificador & $\begin{array}{l}\text { - analisa oficialmente, in loco, o sistema e a documentação para } \\
\text { determinar se eles atendem ao modelo de conformidade (norma) } \\
\text { selecionado e se têm condições de ser certificado }\end{array}$ \\
\hline
\end{tabular}

Fonte: Oliveira e Grael (2007). 


\section{Gestão da qualidade com base na norma ISO 9001}

Conforme Slack, Chambers e Johnston (2001), a gestão da qualidade total é uma filosofia de como abordar a administração da qualidade. É um modo de agir e pensar a produção que se preocupa particularmente com os seguintes assuntos: a) atendimento das necessidades e expectativas dos consumidores; b) inclusão de todas as partes da organização; c) inclusão de todas as pessoas da organização; d) exame de todos os custos relacionados com a qualidade; e) fazer "as coisas certo da primeira vez", como, por exemplo, enfatizando a construção da qualidade desde o design, em vez de apenas inspecionar, e f) desenvolvimento de sistemas e procedimentos que apoiem a qualidade e a melhoria.

Um SGQ incentiva a compreensão, a integração e a utilização de todos os recursos da organização de forma a atender as necessidades dos clientes e satisfazê-los de forma consistente, por meio de melhorias contínuas em todas as atividades. Convém que sua adoção seja uma decisão estratégica da empresa (MAGD; CURRY, 2003).

0 projeto e a implantação de um SGQ são influenciados por necessidades de clientes, objetivos específicos da empresa, cartela de produtos, desenho dos processos, tamanho e complexidade da estrutura da organização, e características de sua cultura (1S0 9001, 2000).

A produção de produtos e serviços com qualidade não é uma tarefa fácil de ser conseguida. Fazem-se necessários o desenvolvimento e a implantação de sistemas de gestão da qualidade nas organizações para que se garanta o comprometimento de todos com o objetivo de conquistar a excelência nos processos e produtos, possibilitando seu aprimoramento contínuo (OLIVEIRA; MELHADO, 2004).

A norma 1SO 9001 contempla, por meio de requisitos obrigatórios, as características mínimas necessárias a um SGQ que tenha foco nos produtos, serviços e seus processos de produção, trazendo benefícios também para fornecedores como para clientes (MAGD; CURRY, 2003).

Alguns destes principais benefícios são: aumento das oportunidades de mercado; redução de custos; fortalecimento da reputação da organização aos olhos das partes interessadas; redução do desperdício (financeiro, temporal e material); melhoria no potencial de competição a partir do aumento da satisfação do consumidor; melhoria no sistema de gerenciamento, e aumento nas margens de lucros e nos ganhos dos empregados (DOUGLAS; COLEMAN; ODDY, 2003).
Existem inúmeras razões para as empresas se certificarem segundo a norma ISO 9001. As principais estão relacionadas à exigência do mercado, à melhoria nos processos e produtos, à melhoria da imagem da empresa, ao atendimento da exigência de grandes clientes, à maior probabilidade de aumento de exportações, ao marketing, etc. (YAHYA; $\mathrm{GOH}$, 2001).

Poksinska, Dahlgaard e Antoni (2002) afirmam que a principal razão para as empresas buscarem a certificação 1S0 9001 está 75\% associada com melhoria da qualidade de seus produtos. A Figura 2 apresenta os principais elementos, e suas interrelações, da norma 1S0 9001.

\section{Gestão ambiental com base na norma ISO 14001}

Existe um grande número de ameaças ambientais à humanidade, como: o aquecimento global da superfície da terra e da camada da atmosfera; o escasseamento da camada de ozônio; o excesso de consumo dos recursos naturais não renováveis, e a poluição global do ar. Estes problemas ambientais têm aumentado exponencialmente a poluição, acelerando o esgotamento dos recursos naturais do planeta (CHAN; WONG, 2006).

Em meio a este cenário, as organizações estão cada vez mais preocupadas com a conquista e a demonstração de melhor desempenho ambiental. lsto pode se dar por meio do estabelecimento de uma política e de objetivos ambientais que permitam o controle dos impactos de suas atividades e de seus produtos e serviços sobre o meio ambiente.

Estas empresas atuam em um contexto no qual a legislação é progressivamente mais restritiva e exigente, as políticas internacionais pressionam pela proteção do meio ambiente e existe uma crescente preocupação em relação às questões ambientais e ao desenvolvimento sustentável (ISO 14001, 2004).

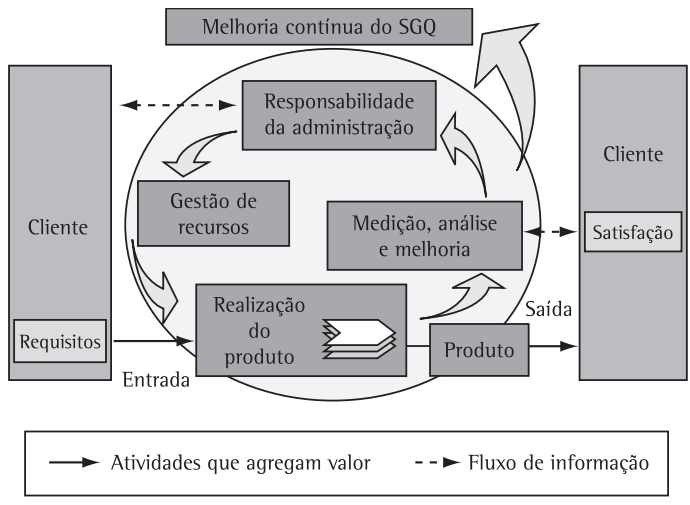

Figura 2. Elementos da 1S0 9001. Fonte: ISO 9001 (2000). 
Para garantir um bom desempenho ambiental, devem ser previstas soluções eficazes para o controle e a redução dos resíduos gerados. 0 desenvolvimento do produto, o gerenciamento da produção e o controle dos resíduos resultantes devem passar a ser tratados de forma integrada. Esta integração requer a profunda consideração do ciclo de vida do produto, desde as matérias-primas utilizadas em sua fabricação até o descarte final dos resíduos gerados.

A norma ISO 14001 deixa clara a necessidade de integração entre os conceitos de qualidade e meio ambiente. A base para elaboração de um SGA é a mesma para a elaboração de um SGQ. Essa equivalência entre os modelos facilita o trabalho das organizações que tenham como objetivo melhorar a qualidade ambiental de seus processos (BISPO; CAZARINI, 2006). A Figura 3 apresenta os principais elementos que compõem a norma ISO 14001 e suas inter-relações.

Segundo Quazi et al. (2001), a ISO 14001 possui uma estrutura que guia a empresa na compreensão e na estruturação de um SGA apropriado. Permite, ainda, o desenvolvimento de algumas ferramentas ambientais de análise e auxilia na definição do ciclo de vida dos produtos.

A norma não define níveis de amadurecimento e desempenho dos processos ambientais nem estabelece valores para indicadores de controle. Desta forma, ela pode ser facilmente adaptada à realidade dos países que a adotam. Não é intenção da norma copiar ou duplicar qualquer sistema regulatório.

Segundo Tan (2005), existem três grandes razões para que as empresas implantem um SGA com base na norma ISO 14001: a) obter a certificação para ganhar vantagens competitivas; b) antecipação de incentivos do governo, e c) poder de influência sobre empresas parceiras.

Importantes pesquisas sobre a certificação ISO 14001 têm se focado principalmente nos seguintes temas: a) procedimentos adotados e resultados obtidos por empresas certificadas;

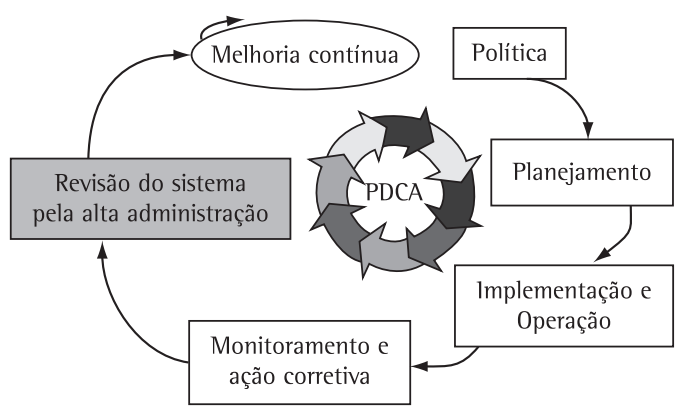

Figura 3. Elementos da ISO 14001. Fonte: ISO 14001 (2004). b) razões que têm levado as empresas a procurarem a certificação ISO 14001; c) benefícios gerados a partir da implantação da $1 S 0$ 14001; d) impressões e atitudes de colaboradores e fornecedores acerca da ISO 14001, e e) fatores críticos que afetam a implementação de um SGA e dificuldades específicas de implementação da ISO 14001 (ZENG et al., 2005).

\section{Integração de sistemas de gestão normalizados da qualidade e do meio ambiente}

A norma ISO 14001 foi desenvolvida com base na ISO 9001 e estas normas possuem muita semelhança e extrema ligação entre si. Ambos os sistemas possuem objetivos similares e induzem a utilização de muitas ferramentas em comum. Desta maneira, algumas organizações buscam potencializar seus resultados por meio da sinergia alcançada com a integração, completa ou parcial, destes dois sistemas (GRAEL; OLIVEIRA, 2007).

0 maior beneficiado pela 1SO 9001 é o consumidor, porque seu foco principal é a melhoria da qualidade de processos e produtos. A ISO 14001 visa gerar resultados para a comunidade global, pois é quem, de fato, usufrui de seus benefícios. Contudo, as indústrias também têm lucrado muito com a certificação ambiental, pois passam a estar habilitadas para os negócios globais e reduzem custos de diversas ordens (MOHAMED, 2001).

Embora existam muitas similaridades entre estes sistemas, é importante ressaltar e compreender suas diferenças a fim de facilitar seu processo de integração. A $1 S 09001$ procura assegurar conformidade às especificações requeridas pelos produtos e, no caso da $1 \mathrm{SO}$ 14001, as atenções estão mais concentradas nas saídas das atividades, que devem estar alinhadas com as políticas, os objetivos e as metas ambientais (ZUTSHI; SOHAL, 2006).

A integração de sistemas certificáveis pode se dar das seguintes formas: a) integração de sistemas utilizando como base a norma 1SO 9001; b) integração de sistemas utilizando como base a norma ISO 14001 , e c) integração de sistemas utilizando como base a norma OHSAS 18001 (Occupational Health and Safety Assessment Series), que não constitui objeto de estudo deste artigo (MOHAMMAD et al., 2006).

A ISO 9001 fornece uma estrutura para definição e implantação de uma linha base de garantia do sistema da qualidade, que é essencial para desenvolver a melhoria contínua dos processos e técnicas, que podem convenientemente servir de apoio à implantação da ISO 14001. 


\section{Estudo de caso}

A escolha da empresa se deu, principalmente, em função da potencial contribuição que seu estudo poderia dar à pesquisa, tendo em vista seu relevante histórico e a correlação positiva que seu nome tem com questões ambientais e da qualidade.

Soma-se a isso o fator conveniência, pois essa empresa tem sede na região da instituição de pesquisa onde foi realizado este trabalho, consentiu a realização do estudo e já estava sendo objeto de uma pesquisa de pós-graduação strictu sensu conduzida por estes autores. A acessibilidade aos dados relativos aos dois sistemas de gestão proporcionados pela sua alta administração também foi um fator decisivo para sua escolha.

A empresa estudada foi fundada em 1965 e atua no setor moveleiro. Produz mais de cem toneladas de móveis/dia, tem 250 colaboradores e fatura perto de 44 milhões de reais por ano. Possui sede no interior do Estado de São Paulo (centro-oeste paulista) e exporta para mais de 15 países da Europa, América e África. Destaca-se na produção de móveis com chapas de aglomerado provenientes de reflorestamento. A empresa foi certificada pela ISO 9001:2000 no ano de 2002 e possui um sistema de gestão ambiental formalmente implantado ainda em fase de certificação, que está relativamente integrado ao sistema da qualidade, além de ter sua gestão baseada no Modelo Prêmio Nacional da Qualidade.

Está, desde 2002, classificada entre as cem melhores empresas para se trabalhar no Brasil e na América Latina, pelas revistas Época e Você S/A.
Também recebeu em 2002 o prêmio de empresa modelo de responsabilidade social do Guia Exame de Boa Cidadania Corporativa e, em 2003, o prêmio CNI (Confederação Nacional das Indústrias) de Qualidade e Produtividade, promovido pela Federação das Indústrias do Estado de São Paulo (FIESP).

Para a coleta de dados, conforme relatado no item Método de pesquisa, foram utilizados os seguintes instrumentos: entrevista com o coordenador responsável pelos sistemas de gestão ambiental e da qualidade, entrevista com três funcionários do nível operacional, além da análise de documentos e da observação in loco. A Figura 4 apresenta o organograma atual da referida empresa.

Conforme se pode observar no organograma, o órgão interno responsável pela implantação e manutenção dos sistemas de gestão ISO 9001 e ISO 14001 é a Diretoria de Sistema de Gestão/Qualidade/RH. O controle da documentação (instruções e registros) dos dois sistemas é executado por um único responsável. Em função disto e do pequeno número de níveis hierárquicos, a comunicação fica facilitada, o que ajuda muito no desempenho da integração dos sistemas de gestão.

A Figura 5 apresenta um resumo das fases de implantação e integração dos sistemas de gestão da qualidade e de meio ambiente na empresa.

$\mathrm{Na}$ fase de planejamento das ações de implantação dos sistemas de gestão, a empresa definiu suas políticas da qualidade e meio ambiente formalmente, porém de forma separada, para que houvesse a certificação de cada um dos sistemas em momentos distintos.

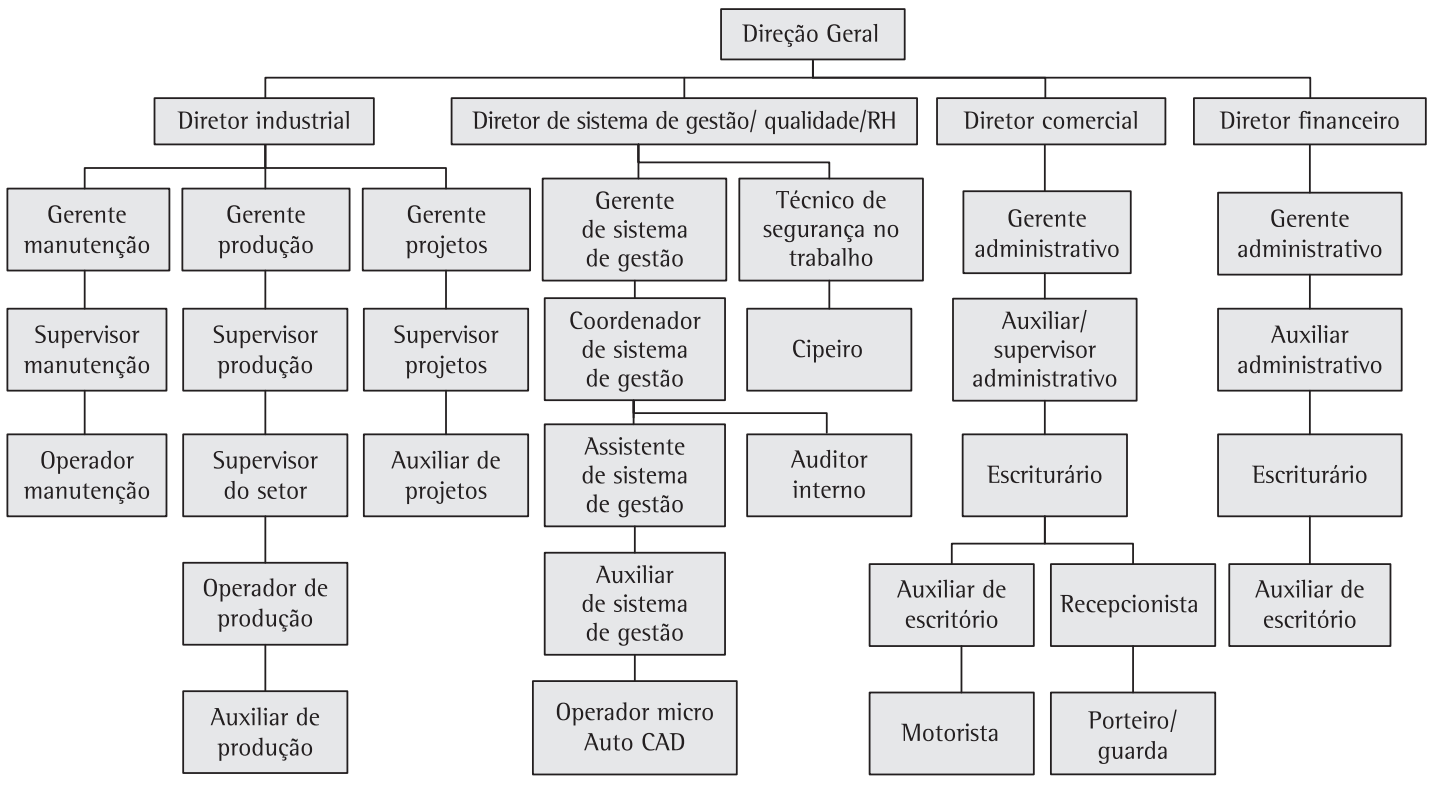

Figura 4. Organograma da empresa estudada. 
Ainda nesta fase, houve a formação dos times da qualidade e ambiental, cada um com seu próprio líder, que era responsável pela disseminação das informações relativas acerca dos sistemas aos outros colaboradores e por eventual esclarecimento de dúvidas. 0 processo de certificação $1 S 09001$ e sua integração com o SGA com base na norma $1 \mathrm{SO}$ 14001 tiveram início efetivo com o desenvolvimento e implantação do Programa 5S.

$\mathrm{Na}$ fase de desenvolvimento, foram identificados os aspectos e impactos ambientais, sendo levantados os pontos críticos para monitoramento dos processos. A partir das recomendações das normas ISO 9001 e ISO 14001, foram elaborados os procedimentos dos sistemas de gestão.

Nesta etapa, elaborou-se o plano emergencial contendo rotas de fuga em caso de explosão do principal resíduo da empresa - o pó de serra - e estabeleceram-se os primeiros indicadores de medição de desempenho. Os treinamentos para ambos os sistemas, realizados pelo departamento de Recursos Humanos (atual departamento de Gestão de Pessoas) eram constantes e intensos. Atualmente, existe um plano anual de treinamento que contempla as necessidades dos dois sistemas simultaneamente.

$\mathrm{Na}$ fase de controle, foram desenvolvidas as principais ferramentas utilizadas para sustentação dos sistemas: análise estatística; gestão à vista; 3QPOC (ferramenta utilizada para estruturar planos de ação - 0 quê? Quando? Quanto? Por quê? Onde? e Como agir?); diagrama de causa e efeito; brainstorming (tempestade de ideias), etc. As auditorias internas dos dois sistemas foram e são realizadas em ciclos independentes, com a justificativa de que os objetivos dos sistemas não sejam confundidos pelos colaboradores.

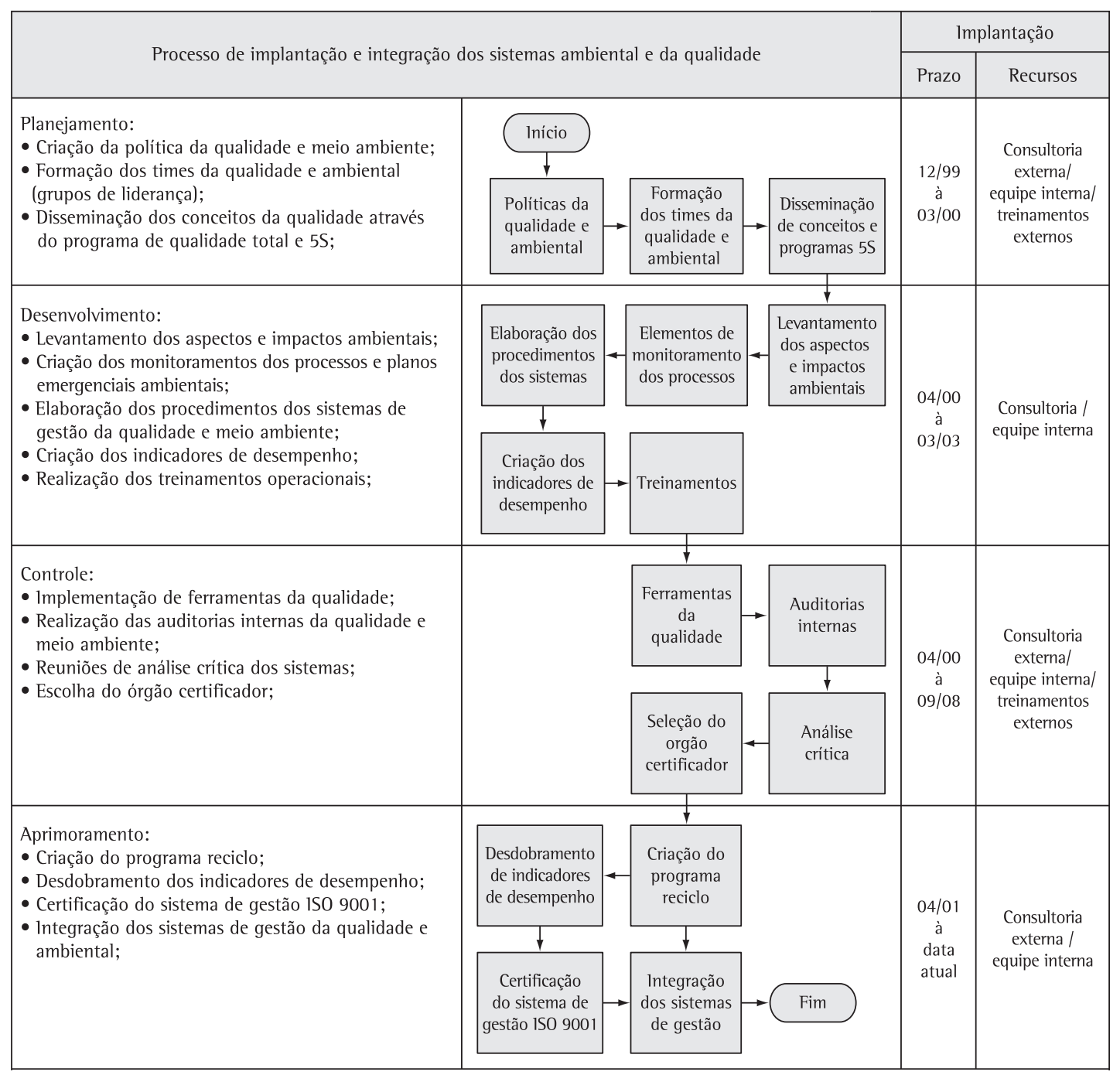

Figura 5. Fases de implantação e integração dos sistemas de gestão ambiental e da qualidade. 
As reuniões de análise crítica eram e ainda são realizadas semestralmente pela alta direção para acompanhamento do desempenho de ambos os sistemas conjuntamente. Nelas são verificadas e revisadas, conforme a necessidade, as políticas, os objetivos, as metas, os planos de ação, os resultados dos sistemas, etc. A escolha do órgão certificador para o sistema de gestão ISO 9001 foi feita na primeira reunião de análise crítica realizada.

$\mathrm{Na}$ fase de aprimoramento, a empresa envolveu a comunidade por meio da realização de algumas ações sociais, como o "Programa Reciclo", que consiste na reciclagem do lixo proveniente da comunidade e da própria empresa, e tem como objetivos principais desenvolver, com os recursos arrecadados, programas de conscientização ambiental nas escolas da cidade onde está instalada a empresa, e auxiliar na capacitação dos colaboradores por meio da realização de cursos de pós-graduação, graduação, profissionalizantes, idiomas, informática, etc.

Nesta fase, também foi realizado um estudo aprofundado acerca da necessidade de desdobramento dos indicadores de desempenho relativos à qualidade e ao meio ambiente como forma de melhorar o sistema de medição da empresa nos níveis estratégico, gerencial e operacional. Atualmente, existem mais de 150 indicadores distribuídos por todos os níveis hierárquicos, mas há estudos em andamento para sua redução.

A integração dos dois sistemas é contínua e pode ser constatada por vários elementos; dentre estes, destacam-se: a integração da documentação, em que um mesmo documento é elaborado com prescrições tanto para qualidade como para o meio ambiente; os treinamentos, que, dentro do possível e quando envolvem questões relativas a estes sistemas, são ministrados para também tratar dos dois temas em conjunto; as atitudes da alta administração, que procura tomar suas decisões relativas a estes dois sistemas sempre considerando suas inter-relações; as inspeções, que, sempre que possível, procuram investigar os elementos de ambos os sistemas em conjunto, e as análises críticas e os indicadores de desempenho, que têm como principal objetivo dar uma visão dos processos que compõem os sistemas de forma ampla e integrada.

Dentre os benefícios auferidos com a implantação/integração dos dois sistemas, segundo as entrevistas realizadas e a documentação pesquisada, destacam-se:

- A satisfação dos colaboradores, que era 78\% em 2003, aumentou para 84\% no final de 2006, conforme pesquisa semestral interna da empresa com 100\% dos seus colaboradores;
- 0 índice de conformidade das entregas dos fornecedores, em função de uma política de disseminação da importância da qualidade assegurada, passou de 63\% em 2003 para 89\% em 2006, conforme indicador interno da empresa, que avalia 100\% das mercadorias recebidas;

- 0 atendimento aos requisitos do produto no processo produtivo passou de 98\% em 2003 para 99\% em 2006, conforme levantamento de conformidades do processo produtivo constantes em seus registros da qualidade;

- A quantidade de lixo - que passou a ter seleção e reciclagem apropriadas e destinação corretamente executada - aumentou 37\% no período de 2003 a 2006, conforme levantamento realizado pela própria empresa;

- 0 nível de destinação correta e o reaproveitamento dos resíduos tiveram aumento de 9\% no período de 2003 a 2006, conforme levantamento realizado a partir dos registros do processo produtivo.

As principais dificuldades identificadas para implantação e integração dos sistemas, segundo entrevista com o seu coordenador, foram:

- Inexistência de controles e inspeções da qualidade no sistema de gestão anterior;

- Ausência de incentivos, como plano de saúde, cesta básica, previdência privada, auxílio educacional e prêmios para motivação do pessoal envolvido direta e indiretamente no processo produtivo;

- Falta de informações relativas à legislação e normas relacionadas a ambos os sistemas;

- Dificuldades de interpretação das normas ISO 9001 e ISO 14001 por parte dos gerentes e colaboradores;

- Falta de capacitação técnica dos funcionários para mapear processos, seus inter-relacionamentos e resultados e, consequentemente, dificuldade para estabelecer e monitorar indicadores de performance;

- Conflitos, desconfiança, sensação de perda, incerteza, falhas de comunicação e distorções na estrutura de poder alimentavam a resistência à mudança;

- Ineficiente sistema de comunicação e dificuldade de acesso às informações devido, principalmente, à falta de quadros de gestão à vista, além de ausência de instrumentos, procedimentos e ferramentas para registrar fatos e disseminar informações necessárias para o controle dos processos;

- Fraco desempenho e capacitação da média gerência, que dificultou a introdução de novos conceitos, como melhoria contínua, cliente/fornecedor interno, qualidade dos processos e produtos, etc.

- Sérias limitações da habilidade e da competência dos funcionários, pois não havia um instrumento eficaz que as medisse eficientemente ou as desenvolvessem;

- Ausência de treinamento técnico para operários, pois não havia preocupação com padrões de qualidade dos processos e produtos. 


\section{Proposição de práticas para integração de sistemas de gestão ambiental e da qualidade}

Baseadas no referencial teórico e corroboradas pelo estudo de caso realizado, apresentam-se, a seguir, algumas práticas para integração de sistemas de gestão ambiental e da qualidade em empresas do setor moveleiro:

\subsection{Compromisso da alta administração}

A alta administração deve considerar o respeito pelo ser humano, suas necessidades e seus anseios como uma das principais "armas" a favor da integração dos sistemas, de forma a criar um vínculo permanente de cordialidade entre todos na empresa e gerar um ambiente de trabalho saudável para inspirar confiança e induzir a execução de processos com qualidade e consciência ambiental.

É importante que a alta direção esteja, dentro do possivel e conforme sua agenda, em contato direto com todos os níveis hierárquicos, acompanhando a execução dos processos e as ações de melhoria, de maneira a fomentar o comportamento pró-ativo e as sugestões de aprimoramento de produtos, processos e de elementos para aumento da integração dos sistemas por parte dos colaboradores.

\subsection{Apoio administrativo, financeiro $e$ pessoal}

A alta administração deve envidar máximo esforço para disponibilizar o apoio administrativo, financeiro e pessoal necessário para solução de problemas detectados pelos instrumentos de gestão e monitoramento de processos dos sistemas da qualidade e ambiental.

Estes esforços devem ter maior intensidade no início da implantação e/ou integração dos sistemas. Devem ser realizadas reuniões frequentes para conscientizar todos os colaboradores quanto à importância e aos benefícios, tanto corporativos quanto pessoais, que os programas da qualidade e ambiental - e, principalmente, a integração destes - podem gerar.

É muito importante que a alta administração realmente tome suas decisões com base em informações provenientes tanto da área da qualidade quanto da área ambiental. Dessa forma, ficam facilitados os processos de integração, além de fortalecer um dos principais instrumentos de mobilização do quadro de colaboradores: o exemplo.

\subsection{Serviços de consultoria}

Ao se contratarem serviços de consultoria para desenvolver e/ou implantar sistemas de gestão ou mesmo integrá-los, deve-se pesquisar e qualificar adequadamente as potenciais empresas a serem contratadas, verificando sua experiência com integração de sistemas de gestão, resultados anteriores obtidos, etc., para que se minimize a probabilidade de sua troca por motivos de não atendimento das necessidades do contratante.

É de extrema importância manter um bom relacionamento com a empresa de consultoria, facilitando sua atuação e aportando efetivamente os recursos previstos, para que os prazos sejam cumpridos conforme cronograma estabelecido e para que os erros com possíveis estimativas de custos sejam minimizados.

\subsection{Coordenação do programa de integração}

Selecionar do quadro de colaboradores da empresa ou contratar por meio de recrutamento externo um colaborador para exercer a função de coordenador do programa de desenvolvimento, implantação e integração dos sistemas. A qualidade e a intensidade de seu treinamento é um item essencial para o sucesso do programa.

Ele será o elo entre a empresa de consultoria e a empresa contratante, além de, geralmente, ser o Representante da Direção (RD) e o responsável pela gestão direta das ações estratégicas referentes à implantação e à integração dos sistemas.

\subsection{Interfaces entre os sistemas}

Identificar as interfaces e os principais processos em comum entre os sistemas certificáveis que se pretende integrar, pois, dessa forma, pode-se planejar a execução de processos únicos e que atendam a ambos os sistemas simultaneamente, reduzindo esforços e ganhando em sinergia, tempo e custos.

É importante mapear detalhadamente todos os processos e suas inter-relações e identificar relações positivas e antagonismos entre produtos, linhas de produção, setores, etc. Desta forma, é possível se fazer uma reestruturação de pontos específicos e gerar diferenciais para os sistemas que estão sendo integrados e para a competitividade da empresa como um todo. 


\subsection{Capacitação técnico-gerencial}

Gerar, por meio de capacitação, conhecimento técnico-gerencial compatível com as necessidades dos sistemas a todos os líderes e colaboradores da empresa, conforme sua necessidade em função das atividades que executa, com a finalidade de desenvolver e aperfeiçoar suas competências.

É interessante que seja traçado o perfil de habilidades e competências dos colaboradores com a finalidade de se criar um plano de treinamento eficaz, de acordo com as necessidades e metas traçadas. Tem de se estar atento, também, às deficiências de comunicação, que prejudicam fortemente a consecução dos objetivos estabelecidos e, consequentemente, a integração dos sistemas.

\subsection{Sistema de liderança}

Desenvolver um sistema de liderança positiva no nível tático da empresa. Esta atitude pode minimizar muitas deficiências no gerenciamento e reduzir consideravelmente a desmotivação dos colaboradores. A ideia é criar um grupo forte e coeso e, dessa forma, quebrar os tradicionais paradigmas de resistência à mudança que tanto influenciam negativamente a implantação de sistemas com base nas normas ISO 9001 e ISO 14001 e, por consequência, sua integração. A capacitação e o desenvolvimento da liderança devem ser constantes.

Isto pode ser alcançado a partir da realização de um minucioso diagnóstico do perfil dos gerentes de nível médio. Nesta fase, é necessário que se identifiquem as potencialidades e os principais problemas relacionados à liderança. Com base nestas informações, deve-se elaborarum programa personalizado de potencialização e/ou desenvolvimento de lideranças que, se bem projetado e executado, trará reflexos positivos para a integração dos sistemas.

\subsection{Prospecção, avaliação e desenvolvimento de fornecedores}

Prospectar, avaliar e desenvolver fornecedores para garantir insumos de boa qualidade e que não agridam ao meio ambiente. Deve-se prospectar no mercado fornecedores que, de preferência, possuam SGQ's e SGA's certificados ou, quando não, que comprovem a preocupação e a evolução contínua dos seus processos em relação à qualidade e à responsabilidade ambiental.

Aconselha-se também instituir um sistema de avaliação do desempenho dos fornecimentos e dos produtos. Esta avaliação deve considerar, além das características específicas dos produtos, elementos relacionados à gestão, como prazo, preço, confiabilidade, flexibilidade, etc.
E, se não houver empresas no mercado com as características desejadas e conformes à necessidade e às condições da organização contratante, buscar desenvolver fornecedores, treinando colaboradoreschave do contratado, subsidiando a implantação de sistemas da qualidade e ambiental, etc., de forma a melhorar a qualidade e o desempenho ambiental de seus produtos e serviços. Insumos fornecidos e serviços prestados por empresas que possuem preocupação com qualidade e meio ambiente podem contribuir consideravelmente com o desenvolvimento e/ou manutenção da integração de sistemas do contratante.

\subsection{Sistema de informação}

Dentro das possibilidades da empresa, sugere-se utilizar um software de gestão integrada (ERP Enterprise Resource Planning) para aperfeiçoar a comunicação entre os diversos setores/processos e os sistemas certificáveis de gestão.

Há determinados elementos - planejamento e controle da produção, processo comercial, suprimentos, manutenção, gestão de pessoas e logística - que aumentam, quando bem gerenciados e integrados, consideravelmente a performance dos sistemas de gestão da qualidade e ambiental.

\subsection{Indicadores}

Desdobrar os indicadores estratégicos em indicadores gerenciais e operacionais, de maneira que todos os funcionários da empresa compreendam como seu trabalho contribui para a empresa cumprir suas estratégias por meio dos sistemas da qualidade e ambiental e eles possam, assim, efetivamente auxiliar no processo de sua integração.

É desejável que este desdobramento contemple os níveis estratégico, gerencial e operacional, e também os principais elementos que permitam medir o desempenho do SGQ, SGA e a efetividade de sua integração.

\subsection{Comunicação com o cliente}

Instituir um eficiente canal de comunicação com os clientes, de forma que seja possível compreender suas reais necessidades e transformá-las em requisitos dos processos e dos produtos, facilitando sua consecução à luz da qualidade e da preservação do meio ambiente. Um dos mais eficazes canais de comunicação é a pesquisa de satisfação, que é responsável pelo levantamento das necessidades reais dos clientes, explícitas ou não.

É importante a criação de um serviço de pós-venda e/ou assistência técnica, quando possivel, como forma de agir sobre os erros ocorridos. Este 
serviço tem a importante função de coletar dados, informações, sugestões e críticas diretamento do cliente. Deve-se incluir nessa pesquisa elementos que permitam averiguar a efetividade da integração entre os sistemas da qualidade e ambiental.

\subsection{Integração contínua}

Por fim, é necessário aprimorar continuamente a integração entre o SGQ e o SGA. Deve-se dar um caráter mais amplo para as análises críticas, contemplando obrigatoriamente os indicadores e a solução de problemas dos dois sistemas conjuntamente.

Devem-se analisar, como exemplos, os gargalos de produção, o índice de desperdícios dos processos, o grau de satisfação dos clientes internos e externos, etc., ao mesmo tempo sob o prisma da qualidade e do meio ambiente, verificando possibilidades de sinergia e as eventuais divergências entre processos para sua potencialização ou redução, conforme o caso.

\section{Conclusões}

Um dos principais argumentos para a integração de sistemas certificáveis de gestão é o efeito positivo que ela tem sobre os colaboradores, conscientizando-os e motivando-os em relação à necessidade de conquistar metas cada vez mais audaciosas, aumentar a qualidade de processos e produtos, preservar a integridade do meio ambiente e do ser humano, e reduzir custos operacionais.

Metas de produtividade progressivamente mais desafiadoras requerem a maximização da eficiência gerencial. Múltiplos sistemas de gestão onde somente um bastaria são ineficientes, difíceis de administrar e de envolver os colaboradores, que invariavelmente questionam se devem dar prioridade à produção ou à burocracia que tais sistemas geram.

É muito mais simples obter a cooperação dos funcionários para um único sistema do que para dois ou mais que sejam gerenciados separadamente. Além do mais, a sinergia gerada pela integração tem levado as organizações a atingirem melhores níveis de desempenho a um custo total muito menor.

Muitos benefícios podem ser auferidos com a gestão integrada de sistemas de gestão ambiental e da qualidade; dentre estes, destacam-se: ganho sinérgico com a execução de tarefas em comum, redução dos custos de produção em função da minimização de desperdícios e melhoria na imagem da empresa perante o mercado, o que possibilita $o$ incremento das vendas.

0 referencial teórico apresentado propiciou a interpretação da realidade da organização objeto do estudo de caso e permitiu a identificação das principais dificuldades e dos benefícios no gerenciamento integrado dos seus sistemas. Também possibilitou 0 devido embasamento da sistematização das práticas para integração de sistemas ambientais e da qualidade propostas neste estudo.

A realização de uma pesquisa qualitativa com base na metodologia de estudo de caso mostrou-se bastante apropriada ao objetivo proposto, pois permitiu o estudo em profundidade de uma determinada realidade sem sua abstração do seu contexto real.

0 estudo de caso apresentou os principais procedimentos utilizados e os resultados conseguidos na implantação de um SGA com base na norma ISO 14001, ainda em processo de certificação, e sua integração com um SGQ com base na norma ISO 9001, por uma expoente empresa brasileira do setor moveleiro.

Os instrumentos de coleta de dados (entrevistas, análise de documentos e observação in loco) também se mostraram bastante eficazes e possibilitaram grande agilidade no levantamento e na interpretação dos dados. Sua realização cumpriu a função exploratória de ambientar os pesquisadores com os principais elementos a serem estudados e contribuiu com o referencial teórico embasando a sistematização e a proposição das práticas para integração de sistemas ambiental e da qualidade.

Como explicitado no item relativo à metodologia científica, as práticas sugeridas neste trabalho foram formuladas com base no referencial teórico e corroboradas com os resultados do estudo de caso, que teve função exploratória. 0 estabelecimento de uma questão de pesquisa factível e relevante e a rígida delimitação dos elementos de pesquisa (escopo: sistemas de gestão ambiental e da qualidade; segmento de atuação: setor moveleiro, e recorte geográfico: centro-oeste paulista) contribuíram para relevância científica (contribuição para a teoria) e mercadológica (aplicabilidade) dos resultados obtidos.

Acredita-se que observando estas questões metodológicas e considerando a delimitação estabelecida ao trabalho e a preocupação com a não generalização estatística de seus resultados, ficou garantido seu rigor científico, elemento essencial à realização de qualquer pesquisa com caráter técnico-acadêmico.

Conclui-se que o objetivo proposto neste trabalho foi alcançado, principalmente com a proposição das práticas para integração de sistemas ambiental e da qualidade. Estas práticas abordam, de maneira geral, os seguintes elementos: alta administração, apoio administrativo, financeiro e pessoal, serviço de consultoria, coordenação do programa de integração, interface entre os sistemas, capacitação 
técnico-gerencial, sistema de liderança, prospecção, avaliação e desenvolvimento de fornecedores, sistema de informação, indicadores, comunicação com o cliente e integração contínua.

Podem ser citadas como limitações desta pesquisa: o caráter introdutório das práticas apresentadas em função, principalmente, da limitação de espaço para seu aprofundamento, uma vez que elas são objeto de estudo de uma pesquisa strictu sensu e se encontram em um grau de detalhamento maior, e a sua não implantação real como um conjunto de diretrizes, pois foram formuladas com base em indicações do referencial teórico provenientes de estudos distintos.

\section{Referências}

BISPO, C. A. F.; CAZARINI, E. W. Avaliação qualitativa paraconsistente do processo de implantação de um sistema de gestão ambiental. Gestão e Produção, v. 13, n. 1, p. 117-127, 2006.

CASTRO, R.; OLIVEIRA, 0. J. Challenges and difficulties of destination and recycling of used tires in Brazil. In: PRODUCTION AND OPERATIONS MANAGEMENT SOCIETY - POMS, 18, 2007. Proceedings...

CHAN, E. S. W.; WONG, S. C. K. Motivations for ISO 14000 in the hotel industry. Tourism Management, v. 27, n. 3, p. 481-492, 2006.

CURKOVIC, S.; SROFE, R.; MELNYK, S. Identifying the factors which affect the decision to attain ISO 14000. Energy, v. 30, n. 88, p. 1387-1407, 2005.

DOUGLAS, A.; COLEMAN, S.; ODDY, R. The case for ISO 9000. The TQM Magazine, v. 15, n. 5, p. 316-324, 2003.

FRANCESCHINI, F.; GALETTO, M.; CECCONI, P. A worldwide analysis of 1509000 standard diffusion. Benchmarking: an international journal, v. 13, n. 4, p. 523-541, 2006.

GRAEL, P. F. F.; OLIVEIRA, O. J. A study on the integration of ISO 9001 and 14001 management systems in a Brazilian furniture. In: PRODUCTION AND OPERATIONS MANAGEMENT SOCIETY - POMS, 18, 2007. Proceedings...

GRÜNBAUM, N. N. Identification of ambiguity in the case study research typology: what is a unit of analysis?. Qualitative Market Research: an international journal, v. 10, n. 1, p. 78-97, 2007.

INTERNATIONAL ORGANIZATION FOR STANDARDIZATION - 1SO ISO 9001. Switzerland: 1SO, 2000.
INTERNATIONAL ORGANIZATION FOR STANDARDIZATION - ISO. ISO 14001. Switzerland: 1SO, 2004.

MAGD, H.; CURRY, A. ISO 9000 and TQM: are they complementary or contradictory to each other?. The TQM Magazine, v. 15, n. 4, p. 244-256, 2003.

MOHAMED, S. T. The impact of ISO 14000 on developing world businesses. Energy, v. 23, n. 3-4, p. 579-584, 2001.

MOHAMMAD, M. et al. Strategies and critical success factors for integrated management systems implementation. In: CONFERENCE ON COMPUTERS AND INDUSTRIAL ENGINEERING - CCEIIE, 35, 2006. p. 1391-1396. Proceedings..

OLIVEIRA, O. J.; GRAEL, P. F. F. A study on the integration of ISO 9001 and ISO 14001 management systems in a Brazilian furniture company. In: INTERNATIONAL ANNUAL EUROMA CONFERENCE, 14, 2007. Proceedings..

OLIVEIRA, 0. J.; MELHADO, S. B. Nova norma 1SO 9000 versão 2000. In: OLIVEIRA, 0. J. (Org.). Gestão da qualidade: tópicos avançados. São Paulo: Thomson Learning, 2004.

POKSINSKA, B.; DAHLGAARD, F. F.; ANTONI, M. The state of ISO 9000 certification: a study of Swedish organizations. The TQM Magazine, v. 14, n. 5, p. 297-306, 2002.

QUAZl, H. A. et al. Motivation for $1 S 014000$ certification: development of a predictive model. Omega, v. 29, n. 6, p. 525-543, 2001.

SANTOS, G. T.; ROSSI, G.; JARDILINO, J. R. L. Orientações metodológicas para elaboração de trabalhos acadêmicos. 2 ed. São Paulo: Gion Editora, 2000.

SLACK, N.; CHAMBER, S.; JOHNSTON, R. Operations Management. 3 ed. London: Pearson Education, 2001.

SUN, H. Total quality management, ISO 9000 certification and performance improvement. International Journal of Quality and Reliability Management, v. 17, n. 2, p. 168-179, 2000.

TAN, L. P. Implementing ISO 14001: is it beneficial for firms in newly industrialized Malaysia?. Journal of Cleaner Production, v. 13, p. 397-404, 2005.

YAHYA, S.; GOH, W. The implementation of an $1 \mathrm{SO} 9000$ quality system. International Journal of Quality e Reliability Management, v. 18, n. 9, p. 941-966, 2001.

YIN, R. K. Case study research: design and methods. 3 ed. Newbury Park: SAGE, 2003.

ZENG, S. X. et al. Towards implementation of ISO 14001 environmental management systems in selected industries in China. Journal of Cleaner Production, v. 13, n. 7, p. 645-656, 2005.

ZUTSHI, A.; SOHAL, A. S. Integrated management system: the experiences of three Australian organizations. Journal of Manufacturing Technology Management, v. 16, n. 2, p. 211-232, 2006

\title{
Environmental and quality certifiable management systems: guidelines for integration
}

\begin{abstract}
Based on theoretical references and a case study centered on a furniture company, the main objective of this paper is to propose practices for integration of environmental and quality certifiable management systems. The case study data was collected via semi-structured interviews with those directly responsible for the two systems and some key collaborators at operational level, via document analysis and in loco observation. Finally, some practices are proposed to integrate these systems relating to the following elements: top-level administration; administrative, financial and personal support; consulting service; coordination of the integration program; interface between systems; technical-managerial training; leadership system; search, evaluation and development of suppliers; information system; indicators; communication with the customer; and continuous integration.
\end{abstract}

Keywords

Integration of management systems. Certifiable systems. Quality management. Environmental management. 